\title{
Forests as Protagonists on Battlefields: the case studies of Rivers Bridge and Honey Hill Through the Lens of a HGIS
}

\author{
Silvia E. Piovan ${ }^{\text {a }}$, Ludovico Maurina ${ }^{\text {a }}$, Michael E. Hodgson ${ }^{\mathrm{b}}$, Marco Filippini ${ }^{\mathrm{a}}$ \\ ${ }^{a}$ Department of Historical and Geographic Sciences and the Ancient World, University of Padova, silvia.piovan@unipd.it, \\ ludovico.maurina@studenti.unipd.it,marco.filippini.883@gmail.com, \\ ${ }^{b}$ Department of Geography, University of South Carolina,hodgsonm@sc.edu \\ * Corresponding author
}

Keywords: Forests, American Civil War, story map, battlefield, viewshed

\begin{abstract}
:
This work is part of the PRIN (Italian Project of Relevant National Interest) project named SYLVA, aimed to investigate the overlapping constructs between biology and artificiality, nature and society, wilderness and humanity. The SYLVA project is managed by four academic units within Italian universities. The University of Padova's unit has the main goal to study the sylvan ( forests) as a "refuge" and the evolution of forest units with human activities, such as illegality-criminality, military and geopolitics, intellectual-recreational-educative, and diversity (biological and cultural). In particular, forests and wood margins play fundamental roles in ecological functions, sources of services, functional and economical benefits. Among the provided services, the "prospect-refuge theory" plays an important role during the battles. Among the different areas and contexts that the Padova's unit is investigating within the PRIN Project, this presentation focuses on role of the forests and their margins in the Atlantic Coast during the last phases of the American Civil War (1864-1865). Two main case studies (Figure 1) are presented: the battles of Honey Hill (30 November 1864) and the one of Rivers Bridge (2-3 February 1865).
\end{abstract}

The main goals of this research are: 1) the construction of a historical geographic information system (HGIS) database, containing both georeferenced small and large-scale historical maps and digitized features acquired from these maps representing forests, routes of armies and battle field features; 2) the qualitative and quantitative analysis of the spatial relationships between forests, paths, locations and shelters; 3 ) the creation of a story map. These goals are applied to both case studies in order to better understand the interactions between forests and humans during the last phases of the Civil War.

This study is characterized by a multidisciplinary geohistorical approach that relies on different sources of data: historical maps, written documents, photographs, satellite imagery, LiDAR, paintings, drawings, newspapers and magazines, field surveys and interviews. Collected data were elaborated and analysed within a HGIS. The historical maps used in this research are classified into four main categories:

The Barnwell and the Beaufort Districts of the Mills Atlas (1825). These maps are at 1:127,000 scale. These maps were used to identify the main features of the landscape such as the road network, main morphological features such as fluvial terraces, ponds, hills settlements, and some general characteristics of the forests, depicted here with two different symbol assemblages for forested wetlands and marches. This geohistorical framework allows comparing and validating information provided by the different sources of data, such as the map of a battle and the related accounts, sketches and memoires by the soldiers or officials who fought there.

Small scale maps of the army's paths (1865). These maps were used to reconstruct the paths of the different armies and as basemaps for georeferentiation of other maps.

Large scale maps and battlefield sketches (1864 and 1865). These cartographical documents came from different sources, such as reconnaissance local maps, technical reports, battles accounts and representations of battlefields by Robert K. Sneden.

War of the Rebellion Atlas (1895). These maps, produced 30 years after the end of the War are at different scales and show armies' paths, trenches, rifle pits and troop's movements as well as the general environmental conditions (topography and vegetation).

USGS topographic maps (1919-2020). These topographic maps at 1:24,000 and 1:62,500 scale, provide evidence of the major changes in the landscape (forest cover and anthropogenic features).

Examples of written records are the Official Record of the Union and Confederate Armies, the Memoirs of General W. T. Sherman and the National Register of Historic Places. Visual sources of data include Harper's Weekly engravings, historical photos, and oblique ground and aerial drone images. 
Both case studies are within the Atlantic Coastal Plain (Low Country) of South Carolina, a land characterized by a rich hydrography and a large amount of freshwater forested/shrub wetlands. The most common tree species are the bald cypress (Taxodium distichum) with a height that can reach $40 \mathrm{~m}$ and has a trunk diameter of $0.9-1.8 \mathrm{~m}$ and the longleaf pine (Pinus palustris) which can reach $30-35 \mathrm{~m}$ and a diameter of $0.7 \mathrm{~m}$.

The battle of Rivers Bridge is an example of how vegetation hindered the advance of Unions troops in crossing the swampy low country between Savannah and Columbia. In their effort to attack the Confederate defences on the Salkehatchie River, the Union's soldiers had to change the original path and build a new corduroy road using local trees to cross the river's bed with their heavy equipment while facing a massive fire from strong heart works.

Another way in which forests and vegetation helped Confederate troops in defending their positions is well represented in the case study of Honey Hill. Before the Union arrival, the ground between the fortifications and the river was cleared of trees by the Confederates. At the beginning of the battle, Confederate troops burned the understory to create a smoke stream in order to delay the Union's advance.

In our approach, we first tried to understand what could or could not be seen from Confederate and Union positions. To address this question, we applied a GIS viewshed analysis to the present-day topography from a LiDAR DEM (Figures $2 \mathrm{a}$ and $2 \mathrm{~b}$ ), which was previously corrected from important modern features such as supraelevated roads and other obstacles. Although this is just a first approximation, it allows us to assess that in Rivers Bridge, without forest cover, the Union troops could have been spotted in almost any positions along the river valley (Figure 2a). This example and other considerations about the role of the forest in the battlefields from LiDAR tree coverage data, historical maps and drone surveys will be presented in both case studies, as well as the story map.

This attempt to reconstruct the factors and dynamics between troops, forest and single trees could have an important role in dissemination of geohistorical knowledge of minor battles, providing new perspectives for local cultural heritage and tourism (such as new information for boards, fieldtrips and historical re-enactments).

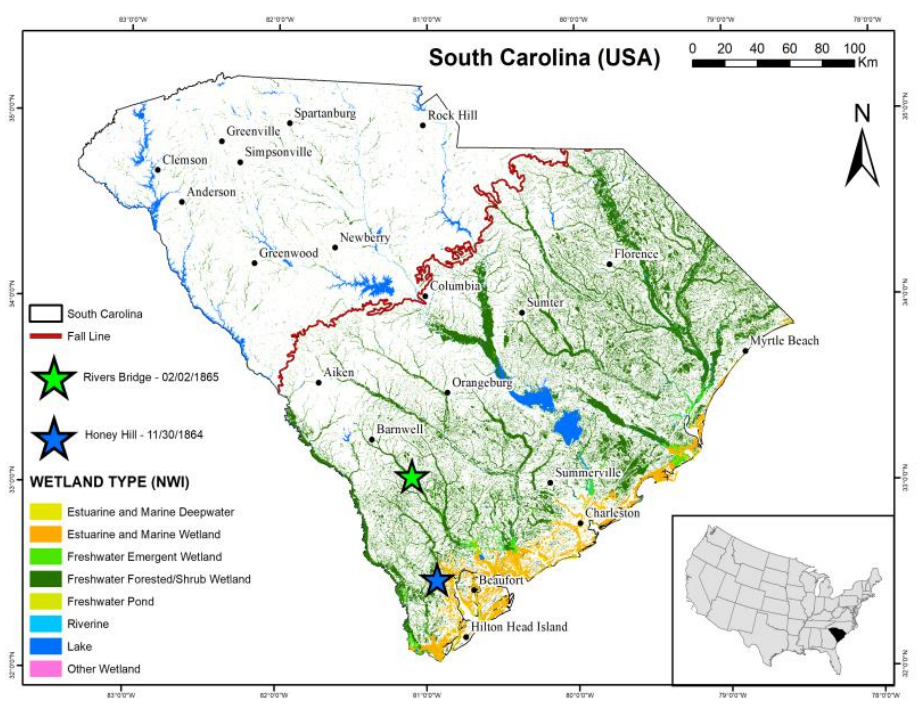

Figure 1. Locations of Rivers Bridge and Honey Hill case studies in South Carolina.
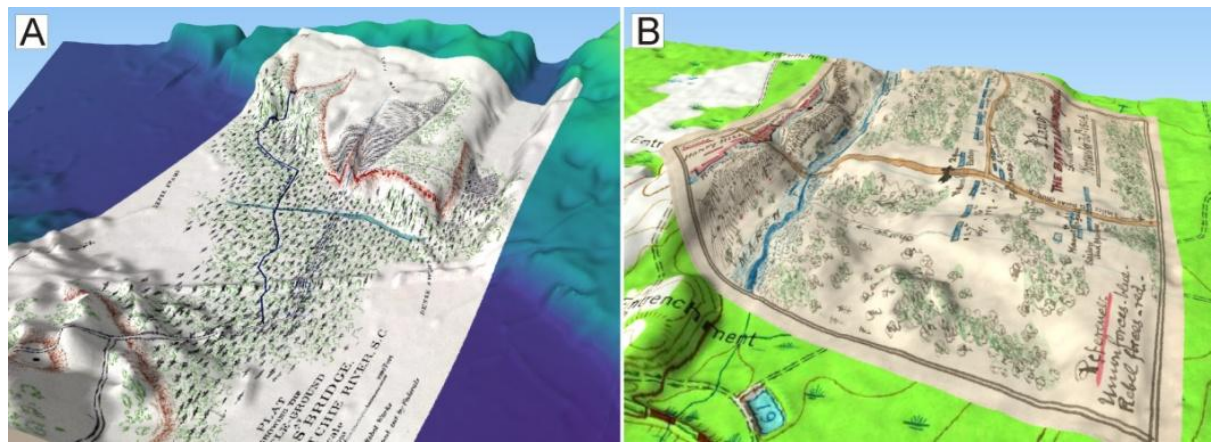

Figure 2. Historic maps of the battlefields wrapped on a LiDAR DEM for Rivers Bridge (a) and on the combined USGS topographic 1:24,000 scale map with LiDAR DEM underlayment for Honey Hill (b). 